\title{
OS FILHOS DE ADÃO \\ Vicinais transamazônicas como entrelugares
}

\author{
THE SONS OF ADAM \\ Vicinal transamazonian, between-places \\ LOS HIJOS DE ADAN \\ Las calles vecinales en la carretera \\ Transamazonicas como entre-lugar
}

\section{Wallace Wagner Rodrigues Pantoja}

Doutorando em Geografia (UNB); Mestre em Geografia (UFPA). Professor da rede estadual do Pará. Secretaria de Educação (SEDUC-PA), Rodovia Augusto Montenegro, Km 10, s/n - Icoaraci, Belém, PA. Email:demithri@yahoo.com.br

\section{Angela Nunes de Oliveira}

Professora da Rede Municipal de Pacajá - PA. Licenciada em Geografia (IFPA). Escola Municipal de Ensino Fundamental Edimilson José Chaves. Vicinal do Adão, Assentamento Rio Cururuí, Núcleo D, s/n, Pacajá, PA. Email: angellanunes@hotmail.com

\section{Maria Idinês Reis de Lima}

Professora da Rede Municipal de Pacajá - PA. Licenciada em Geografia (IFPA). Escola Municipal de Ensino Fundamental Manoel Baiano, Vila do Bode, Vicinal Manoel Baiano, s/n, Pacajá, PA. Email:mariaidines@yahoo.com.br

\section{RESUMO}

Na Transamazônica Paraense, os lugares são inexistidos nas representações geográficas que visibilizam a estrada. $\mathrm{O}$ objetivo é considerar a emergência de entrelugares à beira da estrada constituídos por pessoas de geohistórias diferentes que "se vicinam" e as implicações deste contexto para as leituras de mundo da/sobre a geograficidade transamazônica. O recorte experienciado da pesquisa é o Assentamento Rio Cururuí, Vicinal do Adão, entre Pacajá e Novo Repartimento (PA). Metodologicamente, partimos da pesquisa-ação, registro de memória e de campo, entrevistas com moradores em seus lugares interpretados com o aporte fenomenológico existencial e, concluímos: a) o debate geográfico, no plano educativo, tende a decretar a inexistência dos que vivem à beira Transamazônica ou "Faixa"; b) o sentido de lugar não é estritamente localizável ou demarcável, é não estável, constituindo espaço-limite; c) outra linguagem emerge do entrelugar vicinal, com a potencialidade criadora de ações comunicativas que esclareçam entendimentos geográficos em múltiplas escalas.

Palavras-chave: Lugar, Entrelugar, Vicinais Transamazônicas, Ações Comunicativas, Espaço-limite. 


\begin{abstract}
In Transamazônica Paraense places do not exist in the geographical representations that shows the road, a regional and territorial domination project. The goal is to consider the emergency between -places to the road made of migrants from different geohitories that "whether vicinam" and the implications of this context to the world of readings of/ on transamazônica geographicity. The experienced research focus is on the Vicinal of Adam, between Pacajá and New Repartimento (PA). Settlement Rio Cururuí. Methodologically, we start from action-research, audiovisual recording of interviews with residents in their places, life histories and documentary survey interpreted the existential phenomenological contribution and concluded: a) the geographical debate, the educational plan, tends to declare the absence of They are living on the edge Transamazônica or "strip"; b) the sense of place is not strictly localizable or remarkable is not stable, constituting limit-spaces-s; c) Another language emerges from the between-place with the creative potential of communicative actions to clarify geographic understanding at multiple scales.
\end{abstract}

Keywords: Place, between- place, Vicinais Transamazonica, Communicative Action, Space-limit

\title{
RESUMEN
}

En la Carretera Transamazonica Paraense (Pará-Brasil), los lugares no existen en las representaciones geográficas que son visibles en los proyectos de carreteras de dominación regional y territorial. El objetivo es considerar la emergencia de entrelugares a la orilla de la calle constituidos por emigrantes de geo-histórica diferente que son "Los vecinos" y las implicación de este contexto para la lectura de mundo de y sobre la geograficidad de la Carretera Transamazonica. El recorte experimental utilizado del estudio es la vecinal Adán, entre Pacajá e Nueva Repartimiento (PABrasil), asentamiento Rio-Cururui, impuesto por el estado. A metodología utilizada es pesquisa-acción, con técnicas de registro audiovisual de entrevistas con la población y sus historias de vida, interpretado a través de un aporte fenomenologíco existencial y se concluye que: a) el debate geográfico en el plano educativo, que tiene como tendencia a decretar la no existencia de los que viven el la orilla de la Carretera Transamazonica, b) el sentido del lugar no es específicamente localizable o demarcado, ni fijo, constituyendo espacios-limites C) Otra lenguaje emerge del entre-lugar de las vecinales, con la potencial creadora de acción comunicativa que esclarecen entendimientos geográficos en múltiples escalas.

Palabras Claves: Lugar, Entre-lugar, Carretera Transamazonicas, Acciones Comunicativas, Espacio Limite. 


\section{INTRODUÇÃO: INDO À BEIRA...}

Este texto é um dos movimentos problematizantes das vicinais ${ }^{1}$ à beira da Transamazônica (BR-230), entre Pacajá e Anapu, no estado do Pará. Fruto da aproximação entre a pesquisa de doutorado e o trabalho das/dos professoras/professores de geografia na educação básica nos referidos municípios.

Não trabalhamos com fontes secundárias; a construção deste artigo é fruto de um fazer-saber na experiência espacial à beira da Transamazônica. A fonte não é apenas primária, mas vivida, tanto por nós - uma das autoras vive a Vicinal do Adão - quanto por outros que confiaram seus relatos e não podem figurar explicitamente por razões de segurança. Insegurança e medo, compreensíveis, em um espaço-limite².

O debate proposto pode servir de paralelo e/ou aproximação com outros espaços em situação geográfica coexperiente ${ }^{3}$ ao que trataremos. Porém, não estamos interessados na produção de uma generalidade, mas na interpretação de um contexto vivido. Nesse sentido, não se configura um "estudo de caso", se por estudo de caso entende-se mera constatação de teorias gerais em verificações específicas.

A questão que nos colocamos é: Como se constitui o lugar dos vicinais à beira da Transamazônica? Sabemos que esta pergunta ficará sem o esgotamento de uma resposta. Queremos um principiar da descrição densa em termos geográficos, viabilizando uma abertura comunicativa entre os vicinais e destes com outros espaços. Intencionamos partir do "olhar de dentro", imersos no contexto, constituindo uma metodologia já reconhecida pesquisa-participante -em franco diálogo com o aporte fenomenológico existencial ${ }^{4}$. Para afirmação do olhar situado, além de uma coautora viver assentamento, enfatizamos discursos que se dão no cotidiano à beira da Faixa, famílias que, metaforicamente, constituem os "filhos de Adão", com destaque para os professores e professoras em contexto escolar".

\footnotetext{
Vicinal, também chamada de ramal, são pequenas estradas que começam (ou terminam) em uma via maior ou principal. O termo, de maneira bem sugestiva, significa vizinhança e contiguidade.

2 Por espaço-limite, queremos afirmar a irredutibilidade do espaço onde a vida - e a morte - é decidida, espaços criam-se em situações-limites da existência (JASPERS, 1958) as quais não podemos divisar o futuro, ultrapassá-las ou planejá-las. Discutiremos tal noção mais a frente.

3 Temos ciência do peso epistêmico que a "situação geográfica" carrega. Porém, nossa proposta está muito mais vinculada ao fenômeno da situação-limite (JASPERS, 1958) do que a herança do sítio em relação determinística das ações ou, para falar de um empreendimento metodológico mais recente, da totalidade que se revela e se concretiza na situação singular sobredeterminada por uma estrutura em movimento, como propõe Silveira (1999). Ainda que compartilhemos com a autora a intenção de que: “[...] a situação reafirma a especificidade do lugar e, metodologicamente, aparece como uma instância de análise e de síntese (p. 27)". Somos menos afeitos - ou menos capazes? - de analisar do que interpretar e compreender in-situ.

4 Por fenomenologia existencial entendemos a atmosfera de pensamento que surgiu do encontro da busca de rigor na teoria do conhecimento husserliana e a busca teológico-antropológica de Kierkegaard, que encontra em Heidegger uma unidade compreensiva e compartilhada com outros pensadores (LUIJPEN, 1973).

5 Conversas informais, entrevistas em profundidade e registro de campo e de memória possibilitaram esta aproximação de uma situação geográfica compartilhada, nos ambientes de trabalho, nas frentes das casas, nas cozinhas na hora do almoço, junto a grupos reunidos para jogar dama ou dominó, sobretudo com crianças na escola ou em atividade educativa.
} 
Para uma apresentação didática do texto, inicialmente localizamos o espaço da pesquisa e referimos algumas informações importantes para situar o processo de constituição do lugar. Em seguida descreveremos o lugar como se apresenta aos que vivem e, por fim, relacionamos este viver aos fundamentos de uma geografia do lugar transamazônico que pode emergir na escola vicinal.

\section{LOCALIZAR É DIFERENTE DE LUGARIZAR A VIDA VICINAL!}

A Transamazônica (BR-230) foi construída para catapultar espaços localizáveis, determinados em um feixe retilíneo transversal resultante de uma vontade produtiva em série, pretensiosamente replicando a mesmice do viver ${ }^{6}$ - a partir da colonização dirigida pelo INCRA ${ }^{7}$, nos anos 70 e 80 . A migração compulsória ${ }^{8}$ de nordestinos, coordenada pelo Estado Federal, desencadeou a geografia que, ainda hoje, é definida ou referenciada pela rodovia Transamazônica. Símbolo de um novo processo de ocupação do espaço (GONÇALVES, 2012) e objeto técnico que conecta em rede parte da Amazônia, para que ocorra o uso do território por agentes hegemônicos ou hegemonizados (SANTOS; SILVEIRA, 2001; ARAÚJO; et. all., 2008).

Os conflitos decorrentes tanto do choque de apropriações espaciais diferenciadas (GONÇALVES, 2012), orientação errática do planejamento de Estado e/ou redesenho dos mesmos (BECKER, 2002; COELHO, 2002; HONDA; SEPÊDA; PANTOJA, 2014) e fluxos temporalmente diversos, de diferentes migrantes (ARAÚJO; et. all., 2008), já possuem uma ampla literatura, muito embora, especificamente na Transamazônica Paraense, os trabalhos de cunho geográfico sejam pouco substanciais, sobretudo em uma perspectiva não funcionalista e/ou generalista.

Propomos aqui o olhar sobre o lugar, contextualizado, é bem verdade, em uma região e um território nacional. Estes, muitas vezes, mais imaginados do que vividos (ANDERSON, 2008), ou talvez vividos porque imaginados/imaginários, questão que merece ainda ser aprofundada.

\footnotetext{
6 Não é difícil perceber esta vontade serial e determinadora de cima, em alguns debates emergentes à época do início da construção Transamazônica. Mesmo os estudiosos ditos críticos não eram contrários à construção, mas a sua construção sem planejamento, sem preparo do homem (de fora) e da terra, sem uma colonização racional e firmemente dirigida que replicasse na Amazônia o modelo urbanizante a partir colônias e eventuais centros consumidores (TAMER, 1971).

7 Instituto Nacional de Colonização e Reforma Agrária, criado em 9 de Julho de 1970, pelo Decreto nº 1.100. "O INCRA recebeu a jurisdição sobre as áreas desapropriadas pelo governo federal no Pará, por meio do Decreto Lei no 1.164, de 1º de Abril de 1971, que transferiu à União todas as terras devolutas situadas numa faixa de $100 \mathrm{~km}$ de cada lado das rodovias federais construídas, em construção ou projetadas" (ARAÚJO; et. all., p. 14, 2008), o que foi o caso da Transamazônica.

8 Compulsória porque embora não fosse estritamente forçada, havia um esforço monumental do Estado Federal para reconduzir o problema fundiário nordestino (e de outras regiões do Brasil) para a Amazônia, atribuindo a culpa dos conflitos explosivos pela terra às pessoas que lutavam pela reforma fundiária, e não a divisão desigual/violenta/excludente de terras. Encaminhadas à Região Amazônica, estas pessoas de diferentes pontos do território nacional e mesmo matrizes culturais serão representadas, segundo Nahum (2012) como massa populacional, uma força unitária, naturalizada e manobrável no âmbito do planejamento regional.
} 
A geografia, muito embora tenha no "lugar" um dos seus conceitos centrais, tende a trabalhá-lo justamente como conceito, não como categoria da existência ${ }^{9}$, o que ousaremos aqui, dando continuidade a interlocução de um debate já em expansão. Por categoria da existência, entendemos lugar e sujeito constitutivos um do outro, que "funcionam como duas noções primordiais da experiência humana" (BERDOULAY; ENTRIKIN, 2012, p. 108). É deste lugar e de um sujeito não genérico, que queremos falar: das vicinais transamazônicas e dos filhos de Adão.

Na ausência de mapas mais adequados, ainda por se fazer, utilizamos o que é reconhecível e acessível aos olhos de uma geografia de "sobrevoo". Antes de falar de lugar, falemos de localização. Neste sentido o espaço da pesquisa é matematizável. As duas entradas para o Assentamento Rio Cururuí ficam, uma, na latitude 3874'683" sul e longitude 50 $425^{\prime} 076^{\prime \prime}$ oeste; outra $3^{\circ} 877^{\prime} 431^{\prime \prime}$ sul e 50420'898” oeste, segundo o Google Maps. A leitura do mapa de localização pode ser complementada por uma imagem mais específica do espaço da pesquisa, apresentada logo em seguida.

Figura 1 - Anapu e Pacajá, cortados e constituídos a partir da Transamazônica (BR-230). Elaborado por: Rodrigo Vilela, 2015.

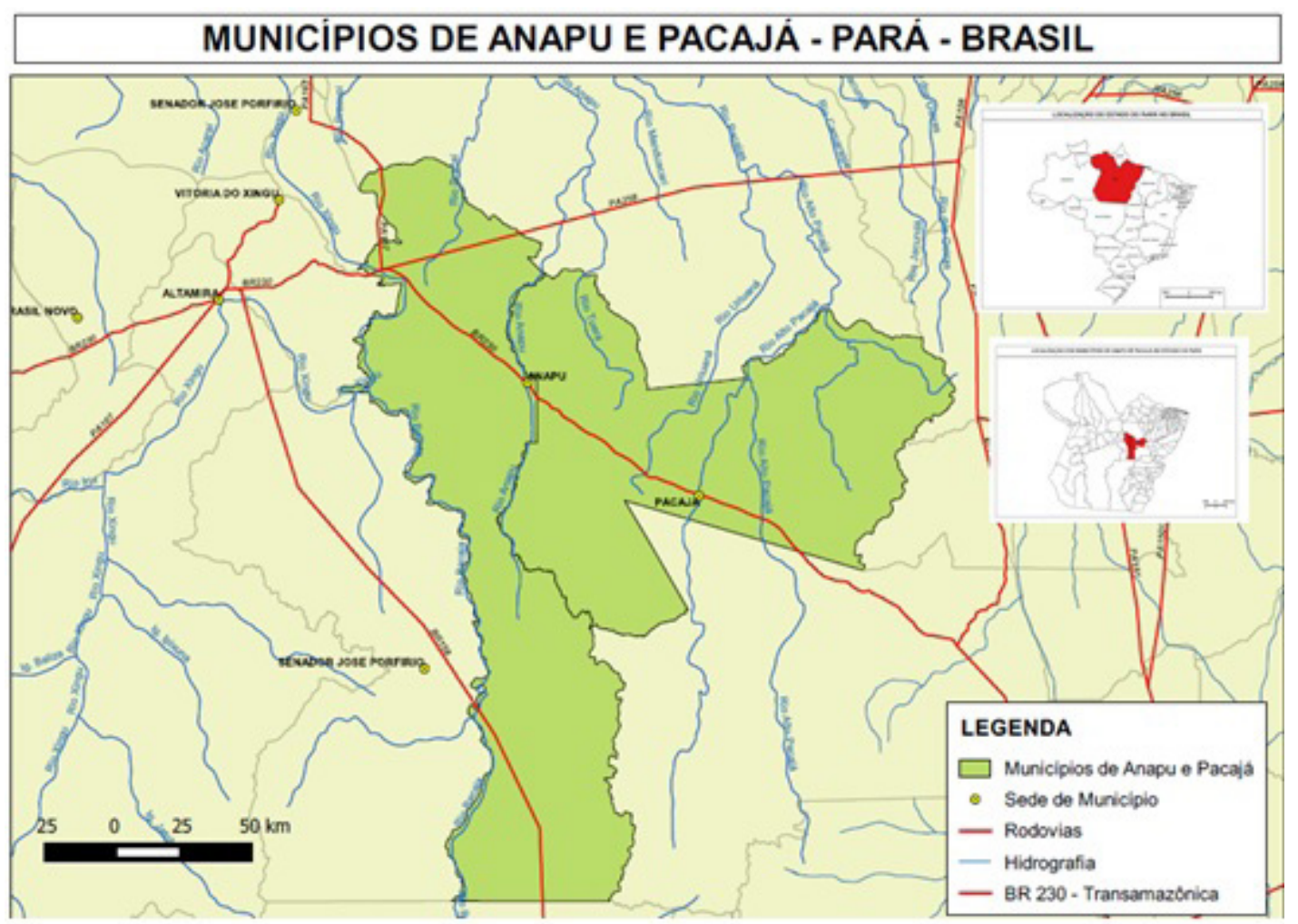

9 Às vezes se trabalha como categoria, mas no sentido de generalidade, abstração e não da existência cotidiana; Além disso, éfrequente a depreciação do conceito de lugar, como nos alerta Relph (2012), seja para destotalizá-lo em espaço (MASSEY, 2009), seja para torná-lo uma derivação de território ou referir-se aos mesmos como sinônimos, como em Haesbaert e Limonad (2007) e Haesbaert (2014) o que, apesar do bom-mocismo, pode ser empobrecedor. Para um entendimento do lugar como categoria, nos aproximamos da proposta frutífera de Berdoulay e Entrikin (2012), embora nosso percurso seja distinto no desenvolvimento categorial. 
Figura 2 - Imagem de satélite referenciando as entradas da Vicinal do Adão, onde se localiza o Projeto de Assentamento Rio Cururuí. Elaboração: autores, 2015.

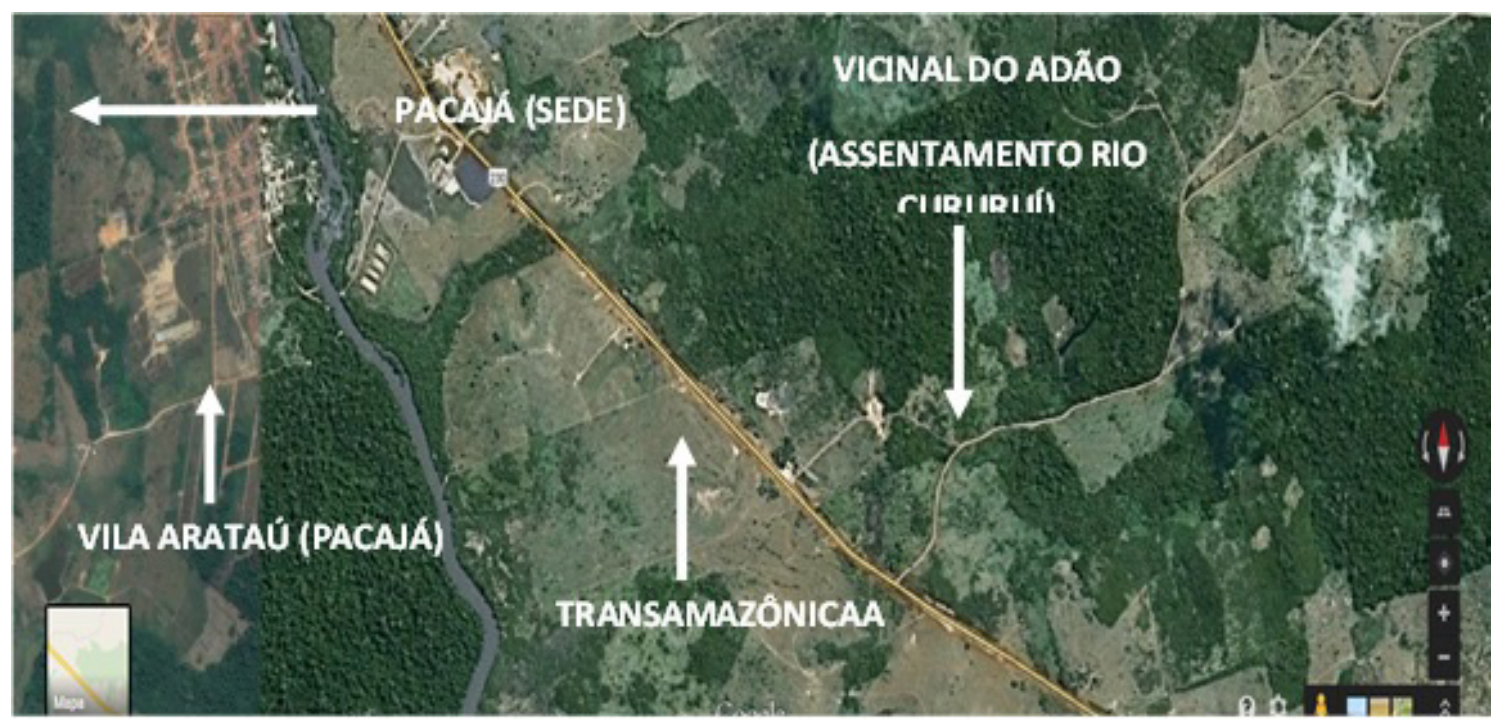

Se a localização é essencialmente geométrica, o lugar não o é. Primeira distinção que já tem escopo geográfico, local e lugar são diferentes, ainda que muitas vezes sejam tomados como sinônimos ou com significado quase idêntico. Termos como "desenvolvimento local", "saber local" e "o local da cultura", não trabalham o local em uma expressão de coordenadas axiológicas, aproximando-se mais do que pensamos como lugar. A proposição de Malpas, inspiradora, enfatiza justamente a relacionalidade das localizações:

The differentiation that belongs to place also bring relationality with it, and one of the features of place is that it is essentially relational, even though this relationality is precisely that which allows places as distinct identities to arise. No place exists except in relation to other places, and every place contains other places that are related within it. The distinctive character of places is thus something that emerges through the interplay of places rather than their absolute separation (which is impossible). I have frequently used the example of oldfashioned topographical surveying to illustrate the point at issue here - and the example is also partly what founds my own use of the term 'topography' [...] . Prior to aerial surveying, and especially prior to the advent of Google Earth, the mapping of a region, which is essentially a mapping of a portion of the Earth's surface (that is, of a certain limit), was done by means of the surveyor's bodily engagement with the landscape (with the surface to be mapped), and through repeated triangulations and traverses between landmarks within that landscape. Not only is the mapping of the region developed in this way, but the region itself can be understood as consisting in this same relational structure. Places within the region are the places that they are through their location within the region, and so in relation to other such places (MALPAS, 2013, p. 4) 
Porém, para efeito da discussão geograficamente informada, a distinção entre local e lugar é necessária, sem perder de vista a relacionalidade das localizações que, representadas, tentam explicitar esta distinção-conexão dos lugares. Além disso, nos interessa na fala de Malpas o "engajamento corporal" - no caso da citação, do agrimensor na topografia, em nosso caso os Vicinais - como caminho para interpretar a distinção entre local e lugar que postulamos.

Malpas traz a questão do engajamento corporal no processo de construção das "coordenadas regionais e entre os lugares de uma região" que, segundo ele, o advento do Google Earth irá desengajar. Entendemos que o desengajamento apenas foi exacerbado e não criado pelas tecnologias digitais, parece historicamente persistente quando se trata de geografizar a Amazônia, a Transamazônica e os lugares que são constituídos à beira.

Localizar é um ato classificatório padronizado, que representa, normalmente no mapa, um ponto ou conjunto de pontos sobre área lisa, como "expressão-síntese" da realidade espacial não apreensível de outro modo. Esta forma de saber supõe uma técnica e uma reprodutibilidade passíveis de penetrar fundo na imaginação popular (ANDERSON, 2009, p. 242) via, entre outros meios, livros didáticos.

Na imagem de satélite, técnica de uma realidade mais real que o mapa, segundo vários entusiastas, a lógica geométrica predomina: a imagem que destacamos revela as linhas que constituem as entradas da Vicinal do Adão, as áreas diferenciadas que demonstram as propriedades, os pastos e a Vila do Arataú, município de Pacajá.

De certo modo, este detalhamento pode nos afastar do "modelo espinha de peixe", tido como um padrão comum ao longo das estradas amazônicas, entretanto bem mais incomum do que imaginamos, ao menos no Pará (SAITO, et. all., 2001) - aqui não temos espinha de peixe, temos aparentes caminhos retorcidos que se esgueiram por terrenos diferentes, uns mais poligonais (pastos), outros menos.

Ponto, segmento, área. Localizar é inferir esta semiologia no cruzamento de linhas latitude e longitude - invisíveis sobre a realidade (ANDERSON, 2009) "inalcançável” aos não especialistas. Não podemos desprezar a importância centralizadora da localização, porém, o local não é lugar.

A Vicinal do Adão não tem uma data de nascimento, mas podemos fornecer uma breve narrativa de criação. 
Em 2006, tive uma bela viagem de $140 \mathrm{~km}$ de distância, uma semana de aventuras, pois ia atrás de um lote para subsistência e assim colher minha agricultura. Pois nessa aventura conheci classes de pessoas, pessoas que também, por aventura, chegaram aqui nesse lugar de muitos sofrimentos e pobreza, chamado Rio Cururuí.

Rio Cururuí é um assentamento de belas paisagens, onde os pássaros cantam e encantam, e os anjos dizem amém, dessa mesma forma busco encontrar o Senhor meu Deus também. Meu trabalho é com amor, faço tudo que posso pelas pessoas e espero a recompensa do meu Senhor. [...] Vivo no núcleo 'D' no lote 66: desde que cheguei aqui, amei este lugar, vim do Breu Branco [próximo a Tucuruí] no ano de 2006 para na Educação trabalhar.

Trabalho desde 2008, com a pretensão deste lugar em breve se desenvolver, sei que Deus está no comando e sabe o que vai fazer, se todos os colonos se unirem vamos ter muito o que colher. Colher... É só se unirem para plantar a agricultura, como arroz, feijão, milho, banana, cacau, farinha e café, neste lugar, Deus é em primeiro lugar. Aqui não tem sua agricultura quem não tem fé ${ }^{10}$.

No relato já se revelam elementos processuais ${ }^{11}$ à compreensão do lugar vicinal transamazônico: a) instabilidade constitutiva; b) centralidade do trabalho na terra; c) unidade tensa entre natureza, produção e transcendência; d) copresença e coexperiência em reunião.

Escolhemos esta fala porque representativa das observações na convivência da pesquisa, amplamente confirmada por outras vozes dolugar. Poderíamos ainda acrescentar outros três elementos: e) diversidade de origem geohistórica; f) geograficidade em criação; g) educação em campo.

Quadro 1 - Elementos centrais na constituição do Lugar Vicinal Transamazônico

Lugar vicinal

- elementos processuais

\section{Expressões vicinais}

Trabalho na terra

O prazer de podermos dizer/que o que temos é de nossa autoridade./

Instabilidade Podendo mandar e desmandar em nossas propriedades,/aqui é tão constitutiva difícil por termos que ser mandado e não podemos/nem fazer nossas roças para colher nossos alimentos./Tem umas entidades que querem só ver nossos sofrimentos [...]

Poema Socorro, Socorro. Anônimo, 2013.

"Clima é melhor, menos perigoso", "A terra é fértil", "Bom para trabalhar na terra" (Respostas-padrão ao tópico: "Pontos positivos de se morar no Assentamento Riu Cururuí", questionário aplicado, 30 respondentes, Out.-Dez. de 2013).

Quando saio deste lugar para escoar minha produção só fico imaginando

Unidade naturezaproduçãotranscendência na viagem e em nosso sofrimento. Por que temos que vender em Pacajá ou em Novo Repartimento. Sofrimentos que passamos ate 3 dias ou mais na estrada com nossas mercadorias ou agricultura em ponto de perder. Mais com a misericórdia do nosso pai do céu, ainda temos chances de vender Autora 2, registro de memórias para a pesquisa, 2014).

\footnotetext{
10 coautora do artigo, em 14.01.2015.

11 Usamos aqui o termo "elemento processual" para facilitar a leitura e marcar a presentificação dos mesmos. Do ponto de vista fenomenológico, estes elementos estão em movimento intencional, portanto, co-constituídos pela reflexão-ação dos indivíduos e do grupo que autoproduz o lugar vicinal e dos pesquisadores em interpretação contextual.
} 
Lugar vicinal

- elementos

processuais

\section{Expressões vicinais}

O avanço da educação do núcleo "D", deu-se no dia 25/03/2008, com uma reunião no lote 29 do mesmo núcleo, objetivando a construção da escolinha. A liderança comunitária era C.S.; A.N. já como candidata para professora [...], mais 23 pessoas dos núcleos " $\mathrm{D}$ ", "H" e "I", trabalharam. Dezesseis homens fizeram limpeza do terreno, as mulheres [...] foram as cozinheiras do almoço

Copresença e Coexperiência dos homens. No dia 26 fizeram o trancado [parede] das folhas do Ubin, [...]. No dia 28 foi feito a cobertura do barraco pelos participantes, A. C., J. R., A. G., A. N., C. R., M., S. C. e M. G. [...] cobriram outro barraquinho, para a professora, que viria da sede municipal, morar. Ela não morou nem um dia, alegando ser perigoso e assustador. Assim, A. N. passou a trabalhar. [...] (Autora 2, registro de memórias para a pesquisa, 2014).

Meu pai era piauiense, o meu avô também./ O meu bisavô cearense, o meu tataravô baiano/ Meu maestro soberano foi o meu tio/ Quem inventou esta canção foi Irislene Teixeira Franc-Elin,/Vindo diretamente do estado de Tocantins/ Atualmente, moro na vila Suribim./ Pois faço muita amizade principalmente com os vizinhos/ Ali onde eu moro há

Diversidade Geohistória tantas complicações./ Nas estradas e travessões é lama no inverno/ É poeira no verão./ Mas estamos esperançosos/ Para estas situações melhorarem./ Pois esperamos que um dia os governantes possam/ A transamazônica asfaltar, pois aqui é pedacinho do Pará/ onde estou a batalhar (Poema de 2004, Relatório de Campo do projeto Educação Cidadã da Transamazônica - I Etapa de formação de educadores/as das séries iniciais. Extraído de autor 1, 2012, p. 4) $)^{12}$.

Paiá, paiá, paiá, paiá. Paiá, paiá, paiá, paiá/ Rebola a mandioca no poço/ Remexe pra fazer o pirão/Balança a peneira caboclo/E fabrica a farinha em montão (bis)/Eu tenho um paneiro bem cheio/Da pura mandioca pra botar,/De molho e assim por três dias/Ficando na água até inchar! [...]/ Música de criação coletiva no trato da mandioca, 2014.

Tivemos a visita do [representante da Secretaria Municipal] e da representante do cartório municipal, que afirmou a impossibilidade de funcionar a escola com 4 alunos presentes, embora houvesse 13 matriculados, ele proibiu que Geograficidade em criação continuasse as aulas. As professoras A. N., J. M. e professoras dos núcleos

Educação em Campo "D" e "H", a líder comunitária C. S. e outros representantes [foram] a Pacajá, [...] em reunião com a prefeitura ficou definido voltarem a trabalhar para as crianças não ficarem sem escola, que passou a se chamar E.M.E.F. José Chaves, com 17 alunos de $1^{\text {a }}$ a $4^{\text {a }}$ serie (Autora 1 , registo de memórias para a pesquisa, 2014).

Elaborado pelos autores, pesquisa de campo iniciada em 2014 .

O quadro é uma explicitação prévia da pesquisa em desenvolvimento. Exploraremos mais na última parte deste artigo. Por hora, cabe uma impressão geral dos elementos processuais colhidos, um convite para nos aproximarmos dos fundamentos complexos da existência do lugar dos "Filhos da Vicinal do Adão".

${ }_{12}$ O texto não foi escrito no assentamento Rio Cururuí, mas como é emblemático da realidade geohistórica diversa dos homens e mulheres que vivem em assentamentos na transamazônica paraense, decidimos torna-la a representação desta realidade partilhada.

Revista da Associação Nacional de Pós-graduação e Pesquisa em Geografia (Anpege). 
Os Filhos de Adão são de muitos pontos do Brasil, carregando consigo não apenas sonhos, mas uma historicidade e, também, lugares vividos, "forçosamente" colocados em condição de copresença, coexperiência e conexidade realizam, à beira da Transamazônica, lugares moventes, feitos de fractais de trabalho e imaginação, atravessados por uma convivência tensa que vai se ordenando e ordenando o mundo próximo e a posicionalidade de indivíduos e famílias neste mundo, mas sempre com a perspectiva da instabilidade vivamente refeita - pelo trabalho que falta ou frentes de trabalho abertas em outras propriedades ou cidades; pela continuidade da educação formal, pela visão quase desesperada que alguns têm quando chegam ao assentamento e decidem voltar após alguns dias ou meses de tentativa frustrada de co-constitução em um não-lugar ${ }^{13}$.

Vicinal, em estado de dicionário, significa "que é contíguo ou muito próximo; vizinho". Tem um sentido que podemos vincular ao debate geográfico, sobretudo na vertente humanista, de base fenomenológica e existencialista, que enfatiza o pertencimento, a criação do aconchego, pautado em percepções e sentimentos de proximidade (TUAN, 2013) que conectam ambiente e ser (TUAN; 2012, 2013), em um contexto cultural e historicamente dinâmico (MOREIRA, 2012, entre muitos outros). Experimentado como fundamento de nossa conexão com o mundo, centrado na reunião humana (RELPH, 2012). Malpas (2013) projeta o lugar como conexão do ser-com-o-mundo, o que possibilita desdobramentos para além do lugar, mas só possíveis tendo este como fundamento - categoria existencial.

Portanto, soa sem consistência a afirmação de que "um conceito nunca é a coisa mesma (esse horizonte sempre buscado e jamais alcançado pela fenomenologia, de adequação da consciência com o mundo-aí) [...]" (GALLO, 2003 apud HAESBAERT, 2014, p. 30). Justamente porque é este "horizonte jamais alcançado" que move o campo interpretativo da ciência, não no sentido de adequação da consciência com o mundo, mas de compreensão do mundo pelos seres que o buscam - pela persistência na busca, no desvelamento, que não é só descoberta, mas criação e recriação do mundo (FEYEREBAND, 2010) - partilhando suas buscas e descobertas parciais, mais ou menos bem sucedidas, dependendo dos contextos históricos, espaciais e culturais que vivem e projetam.

É óbvio que o conceito é um devir, o que não é óbvio - ou, intencionalmente escondido - é que ele pode ser um "antevir" que adequa a realidade pesquisada de uma maneira imperialista, tendo em vista a pretensa confirmação de uma teoria geral e sua objetividade, denunciada por Feyerabend (2009). Evitaremos esta atitude.

\footnotetext{
${ }^{13}$ Não-lugar aqui não é o tratado por Marc Augé (1994), os espaços da supermodernidade, mas a simples não constituição entre ser e mundo em uma existência possível, sobretudo pela impossibilidade do engajamento corpóreo em uma situação geográfica; realização da copresença, coexperiência e conexidade em um dado espaço que não é realizado como um lugar. Obviamente, também ocorrem outros processos, como a deslugarização por expulsão, violência, destruição de vínculos e projetos de vida e mundo, não incomuns em vicinais à beira da Faixa. 
Os elementos centrais que elencamos podem ser reunidos em um núcleo processual que projeta-condiciona-cotidianiza o lugar vicinal. Nossa inspiração parte de Heidegger, para pensar esta visão global dos que vivem a vicinal no espaço e no tempo, na medida em que:

Portanto, a totalidade existenciária do todo-estrutural ontológico do Dasein deve ser formalmente apreendida na seguinte estrutura: o ser do Dasein significa: ser-adiantadoem-relação-a-si-em (-o-mundo) como ser-junto-(ao-ente-do-interior-do-mundo que vemde-encontro) (HEIDEGGER, 2012, p. 539).

De maneira mais didática e de onde iniciamos nosso percurso que levou a Heidegger, citamos Cerbone (2012, p. 85): "A fórmula de Heidegger contém três momentos ou aspectos, que podem ser descritos e analisados em relativa independência, mesmo que os três sejam, ao fim e ao cabo, inseparáveis um do outro. Os três aspectos são: 1) adiante-de-si-mesmo; 2) já-em (o-mundo); 3) sendo-junto-a (entidades-encontradas dentro-do-mundo)”.

Porém, diferente de uma "fórmula" do ser-no-mundo ${ }^{14}$ em sua relacionalidade (a estruturado-cuidado argumentada por Heidegger como uma essência ontológica), enfatizamos o caráter concreto da realidade vicinal em relação dialógica com a proposição heideggeriana.

Esta explicitação da estrutura de relação do ser-no-mundo oferece algumas vantagens interpretativas: 1. Valoriza o movimento contextual dos indivíduos e do grupo; 2. Historiciza o espaços de relações a partir da vida dos indivíduos; 3. Possui uma abertura para o serno-lugar; 4. Está engajada em uma estrutura-do-cuidado de si e do outro, que é (se) compreender e (se) importar; 5 . Pode ser subvertida se a realidade vivida exigir outros caminhos de interpretação; Além do que, quando falamos de diálogo, enfatizamos a necessária dialética do abstrato-concreto, apenas não quisemos explicitar isto porque, como Merleau-Ponty (2012, p. 93) nos adverte: “[...] a dialética é instável, no sentido que os químicos dão a palavra; assim o é essencialmente e por definição, e de tal modo que nunca pôde formular-se em tese sem desnaturar-se e, se pretendemos conservar-lhe o espírito, talvez seja preciso mesmo não nomeá-la”.

Para tanto, nos concentraremos em um destes elementos, pelos limites deste artigo e para apresenta-lo processualmente: a geograficidade em criação.

${ }_{14}$ De maneira breve e correndo o risco de simplismo, entendemos por ser-no-mundo a existência que se realiza em ato, na situação com os outros e deles não se pode apartar para fazer escolhas, mas é constantemente lançado neste campo de presenças não redutíveis - mergulhado nesta trama densa de copresenças, incluindo a sua - onde, aí mesmo, precisa refletir(se), realizar(se) e escolher(se). 


\section{LUGAR COMO EXISTÊNCIA EM ESPAÇO-LIMITE}

Uma dos processos constituintes do lugar vicinal no Assentamento Rio Cururuí, Vicinal do Adão, é a geograficidade em criação, que destacamos do conjunto de elementos processuais do Quadro 1. A ideia foi desenvolvida por Dardel (2011) e explicita que há uma geografia em ato antes de uma ciência geográfica, ou seja, a vida é geográfica e por isso existe uma ciência para compreender esta realidade vivida.

A geograficidade é inerente ao ser humano em seu processo de espacialização, mas não supõe uma tipologia padronizada. Não é possível pensar a geograficidade sem uma forte sensibilidade ao contexto de sua constituição.

Dizemos que a geograficidade está em criação, porque as famílias da Vicinal do Adão foram, literalmente, lançadas neste meio! Como o Assentamento Rio Cururuí foi criado em 2005, já podemos dizer que há "filhos de Adão" naturais, crianças que nasceram neste lugar. Porém, de certo modo, também são filhos, embora pais e mães, os que foram lançados nos núcleos - hoje, oficialmente vilas - que constituem o assentamento. O croqui a seguir revela a distribuição nuclear.

Figura 3 - Croqui do interior da Vicinal do Adão, Km 280 da Transamazônica Paraense. Assentamento Rio Cururuí e seus Núcleos (Vilas), do A (o mais próximo da Transamazônica, $50 \mathrm{~km}$ adentro) ao J (que não consta no croqui por ser recente, $10 \mathrm{~km}$ a oeste do Núcleo $\mathrm{F}$ ). $\mathrm{O} \mathrm{B}$, que não possui escola, está a 10 km a oeste do D. Fonte: autores, 2014. Elaboração: Prof. Sandro Jr, 2014, sem escala.

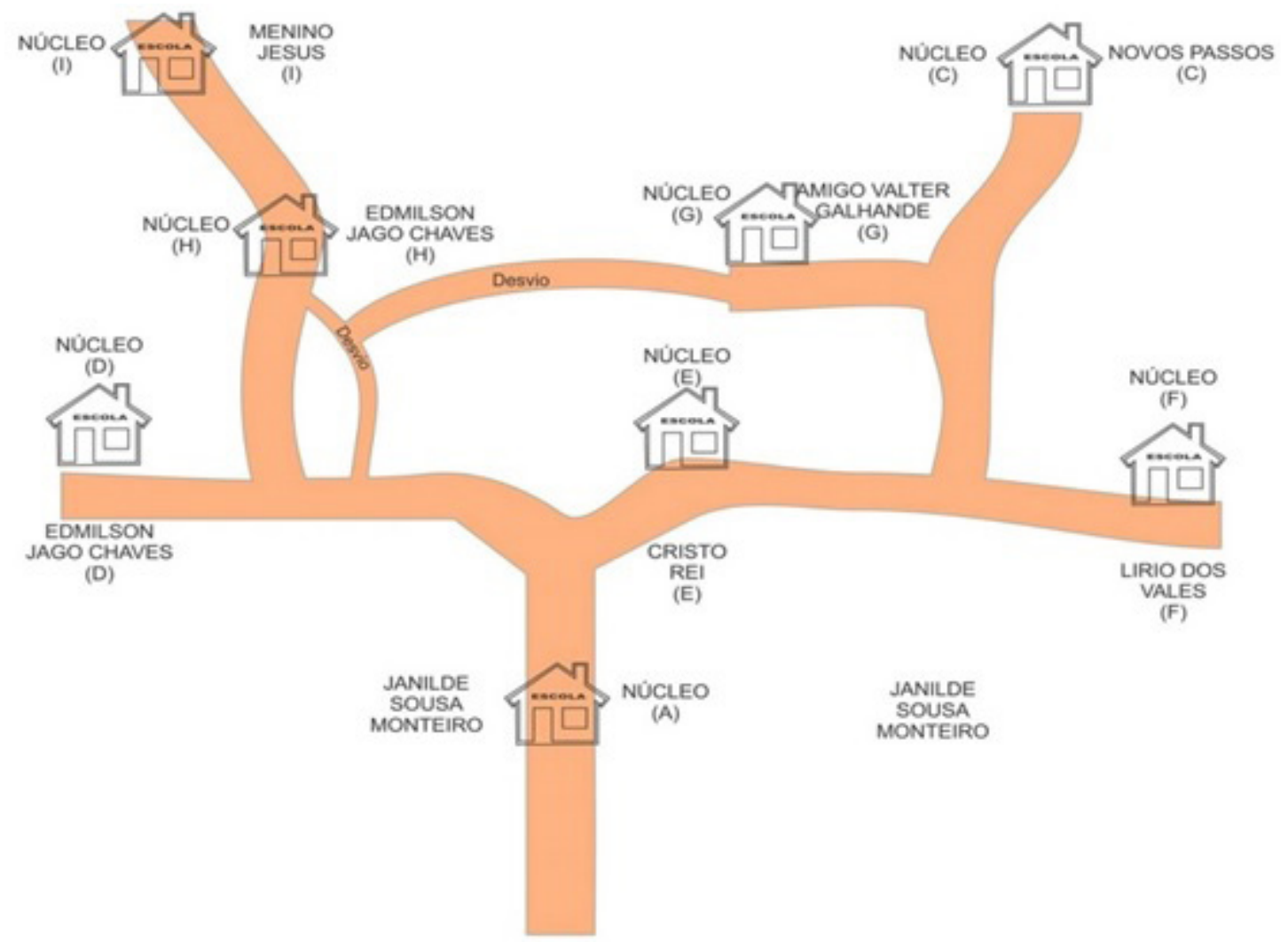


Criar o lugar ${ }^{15}$ é um processo complexo e, muitas vezes, menosprezado por tendência materialista-idealista (SARTRE, 2002), que reifica a consciência humana ao privilegiar as coisas e não o sujeito da ação (SARTRE, 2002; YAZBEK, 2008). Porém, nenhuma criação se dá sem concepções que condicionam e são condicionadas criativamente. A experiência de ser "lançado a este futuro", revelador de uma condição (passado) de existência que rearranja o cotidiano (presente) dos "Filhos de Adão", se explicita na geograficidade emergente e fundante do lugar vicinal.

A escola é um ambiente privilegiado para compreender a realidade geográfica nas vicinais porque é o lugar da reunião diária das crianças e jovens do campo - os Filhos (dos Filhos) de Adão - em formação e, por isso mesmo, sujeitos de um projeto de mundo que a educação intencionalmente inscreve. Em específico, a disciplina geografia, dada a função básica da mesma que, segundo os Parâmetros Curriculares Nacionais (PCNs):

[...] oferece instrumentos essenciais para compreensão e intervenção na realidade social. Por meio dela podemos compreender como diferentes sociedades interagem com a natureza na construção de seu espaço, as singularidades do lugar em que vivemos, o que o diferencia e o aproxima de outros lugares e, assim, adquirirmos uma consciência maior dos vínculos afetivos e de identidade que estabelecemos com ele. Também podemos conhecer as múltiplas relações de um lugar com outros lugares, distantes no tempo e no espaço, e perceber as marcas do passado no presente [...] visa à ampliação das capacidades dos alunos, do ensino fundamental, de observar, conhecer, explicar, comparar e representar as características do lugar em que vivem e de diferentes paisagens e espaços geográficos. (BRASIL, MEC-SEB. 1998, p. 67).

Há, portando, uma clara articulação entre leitura de mundo, geografia e lugar. O que possibilita relacionar a realidade geográfica com a existência dos filhos e filhas dos assentados no Rio Cururuí. A fala da professora é emblemática neste sentido:

O que eu gostaria de pedir, que eu tenho os outros colegas também [olhando para a caneta
que segura, pensativa] é... deixar assim, tipo um recado. Que eles pudessem também [silencia,
visivelmente emocionada, olha para câmera e entre lágrimas levanta a mão como que para
esperar, olha pela porta, para o ambiente lá fora, seu quintal] é visitar a gente porque a gente
aqui, é como vocês vê assim, um pouco dificultoso mermo, como o povo fala. Mas a gente
precisa assim de mais visita assim, de pessoas que [voz embargada, ainda olhando para o
quintal] que têm conhecimentos, que possa dar mais incentivo pros jovens, para os adolescentes
[novas lágrimas, olha para a caneta que manuseia, respira e volta a olhar para o quintal] que
a minha vontade era que esses adolescentes possam ter um futuro melhor amanhã, possam
ser, digamos assim um vereador, um prefeito, um médico, que saia daqui para estudar fora
[faz um movimento com a mão identificando a saída], mas que eles possam voltar [faz o
movimento identificando a volta] ${ }^{16}$

15 Ao promover uma aproximação entre concepções nietzscheana, fenomenológica e marxiana (SCHMID, 2012) Lefebvre chega à espacialidade dialeticamente trina. Não perdemos de vista a importância deste referente, mas o aspecto criador tem um sentido mais "lugarizado" e "cultural".

${ }_{16}$ Autora 1, registro de memória em 14.09.2015. 
Ir e voltar (o que também pode significar nem aqui, nem lá) - estar no entrelugares (BHABHA, 2013), uma condição de existência vicinal que repercute no processo de aprendizagem de uma visão de mundo articulada histórica e geograficamente ao lugar. Cabe aqui uma aproximação das precedências e merecedências ${ }^{17}$, do sentido de entrelugar, para, em sua explicitação nos colocarmos sem acomodações simétricas.

O entrelugar, também referido, segundo Hanciau (2005) como in-between, espaço liminar, zona de contato, espaço intersticial, etc. É uma construção marcadamente póscolonial que se revolta contra os binarismos e polarizações de caráter essencialista, evocando, sobretudo no planto da literatura, a condição radicalmente viva do colonizado que se reinventar entre sistemas de compreensão díspares, justapostos, ambíguos que é realidade colonial lhe impôs.

Porém, sem perder de vista este referente, o que chamamos de entrelugar é antepredicativo nos gestos, fala e choro da coautora, este espaço em transito que, a um só tempo: a) tem negada a sua existência no plano político e representativo geograficamente; b) produz angústia por ser um espaço-limite da existência; c) expressa reunião de múltiplos, tensa e afetivamente constituído; d) é permanência e deslocamento, ambiguamente condição para a história como continuidade e espaço para o rompimento tendo em vista um novo outro; e) é fratura existencial, mas também amplifica conexões, projetando um sentido comum aonde outros só enxergam a ausência de sentido; f) espaço da comunicação impossível de compreensão translúcida - como ação criativa; g) conexão humanamente possível, com toda a distância que não é redutível por um mapa de um profissional com olhar de sobrevoo e paralisante, ou medusado (MERLEAU-PONTY, 2012).

Ao olhar para o quintal busca o ambiente reconhecível para as suas palavras, impregnadas de afetividade e conexidade com o mundo com os dois pés "fincados" no seu lugar de existência (TUAN, 2013; MALPAS, 2013) que também é coexperienciado com os estudantes. Revela um tipo de olhar que é saber - as dificuldades, as possibilidades, o apreço; estão ali, juntos - e direciona este saber para um anseio de encontro, com os outros e seus saberes, para autoreconhecimento e coreconhecimento existencial.

\begin{abstract}
Enquanto existência possível (Existenz) somos liberdade. Em sua liberdade, a existência sabese em relação com a transcendência pela qual se oferece a si mesma. A realidade de nossa existência é o eu em seu devir temporal. Está em nosso amor, fala e é nossa consciência; pois põe-nos em relação com os outros e é nossa razão (JASPERS, 2011, pp. 44-45).
\end{abstract}

${ }_{17}$ Fazemos referência a uma fala finamente irônica do cineasta de Mateus Moura. 
Esta maneira de pensar a existência - como liberdade em contexto e relação com os outros - exige uma reflexão sobre o sentido genérico de lugar que os PCNs de geografia corroboram. De certo modo, tendendo a um essencialismo do lugar que parece chocarse com a fala da professora (e não é a única a falar) e a realidade vivida nas vicinais, onde a relacionalidade ${ }^{18}$ se coloca como central à própria existência e compreensão do sentido de lugar.

Soma-se a isto que é nesta relacionalidade que está emergindo a geograficidade dos Filhos de Adão, afinal, as vilas são formadas por famílias oriundas de diversas partes do Brasil, ocorrendo um fluxo constante de entrada a saída de famílias, o que acentua a instabilidade constitutiva, um elemento inerente a estes lugares-vicinais - um tipo de "fricção geohistórica" que constitui o espaço vicinal de maneira sempre parcelar, fragmentária e até violenta.

As pesquisas em educação do campo revelam a escola como encontro de trajetórias e, ao mesmo tempo, espaço de exercício de reunião do diverso. As posições são posições individuais (singularidades) e, também posições coletivas e partilhadas que se projetam (transcendência). São escolas com diferentes faixas etárias, multisseriadas, em condições infraestruturais temerárias e pressionadas por um fechamento massivo (HAGE, 2005; 2011). Por outro lado, é o ponto "absoluto" do encontro e expressão de luta coletiva (OLIVEIRA NETO, 2015), por parte de indivíduos e grupos em formação educativa que, não raro, estão em uma condição de deslocamento constante, em mobilidade por trabalho e condições de vida.

Por isso, a generalização e congelamento do sentido de lugar não dialogam com a existência e os sentidos constituídos na relação entre os que o vivem e os que não o vivem. A escola, como espaço de formação de um saber geográfico, passa a ser também um espaço de encontro entrelugares, uma relacionalidade que constitui o exercício de posições, uma efetiva existência individual e coletiva, já que "Enquanto existente (Dasein), ser objetivo, nós somos a diversidade dos seres individuais se afirmando a si próprios [...] Enquanto existência (Existenz) somos devir em relação à transcendência, no fundo das coisas" (JASPERS, 2011, p. 45).

A transcendência tem um caráter temporal, espiritual, consciente e relacional. Não se constrói existência sem relação com os outros e, na perspectiva dos lugares, não há existência sem conexidade entrelugares. Temporal porque implica um devir, uma temporalidade vivida em termos de projeto-condição-cotidiano de que já falamos e desafia professores e estudantes em situação vicinal. Espiritual porque não é estritamente objetiva, não pode ser,

18 Por relacionalidade entendemos a conexidade da situação geográfica (em coexperiência e copresença) com outras escalas/ espaços do mundo, ou seja, as existências não copresentes e coexperientes, mas que podem estabelecer ligações vivas de compartilhamento. 
carrega o signo da subjetividade inerente à existência e dialoga com as crenças partilhadas, não sem tensões, dos vicinais que se nutrem na luta diária de criação do lugar possível ${ }^{19}$. Consciente porque possibilita uma avaliação de projeto e partir do conhecimento do contexto vivido. Relacional, por fim, porque não se pode existir sem o(s) outro(s), sem a reunião e a diferença que marca a presença irredutível de cada existência.

A escola, na Vicinal do Adão, passa a ser um espaço de reunião para que a existência se efetive. Porém, também é - via Geografia disciplinar - espaço da inexistência, nos termos que propomos consubstanciados em Jaspers (2011), na medida em que:

Para nossa região, o livro didático que vem de geografia, mais especificamente, ele é um livro com um conteúdo, assim um pouco, distorcido da realidade da realidade de nossa região [pressiona a mão na mesa, marcando o lugar]. E quando se fala de nossa região mostra apenas a Transamazônica em si, como se só existisse a Transamazônica, não existisse as vicinais, as vilas... e [só existisse] os dois municípios como Altamira e Marabá. Então, o pouco que se mostra da nossa região é isso, basicamente o livro está voltado para a região Sul e Sudeste, fala-se muito pouco de nossa região $0^{20}$.

Esta não é uma situação restrita, é uma realidade na Transamazônica e em grande parte das escolas no campo amazônico (HAGE, 2005). Esta desconexão comunicativa entre os materiais didáticos e a realidade dos lugares cria um tipo de deslocamento no "entrelugares" - pelo não reconhecimento de si, de suas paisagens e de seus espaços em livros que produzem mais representações estereotipadas (BONFIM, 2012) do que uma comunicação esclarecida entre os lugares que formam o território nacional. Nesse sentido, como construção da relação entrelugares para efetivo auto e co-reconhecimento, não estamos mais falando de invisibilidade, mas de inexistência - inclusive de inexistência de conflitos reais nos lugares, como a fala do professor explicita:

A maioria dos professores que está trabalhando hoje, na região de Pacajá e Anapu, próximo a estas grandes áreas de latifúndio que tem conflito não toca no assunto [...] prefere pular esta parte do conteúdo e não toca no conflito agrário [fala com um olhar tenso] ${ }^{21}$.

A existência, na medida em que não se efetiva pela articulação comunicativa entrelugares, abre espaço para que um tipo de medo normalizado se apodere do processo educativo, tendo em vista a criação de um conteúdo mergulhado em medo e distanciamento das vivências concretas ao lugar - e seus conflitos - o que fragiliza a transcendência (relacionalidade) da formação dos jovens e crianças vicinais.

19 Como já destacamos anteriormente, os movimentos de ir e vir, de não estar em um "onde" estável, produz abandonos, fugas, desistências, não comum algo excepcional, mas como uma realidade diária para muitos vicinais.

20 Professor de Geografia, Anapu. Entrevista realizada em 16.09.2015.

${ }^{21}$ Professor de Geografia, Anapu. Entrevista realizada em 16.09.2015. 
Entre os dias 17 e 19 de setembro [2010], 13 trabalhadores do PA Rio Cururuí, foram assassinados [...]. A causa geradora desta estúpida violência são os interesses de madeireiras que, para obter lucros cada vez maiores, corrompem funcionários públicos e lideranças de assentamentos semeando a sizânia da ganância e da discórdia entre os assentados da reforma agrária e de outras comunidades (COMISSÃO PASTORAL DA TERRA, CPT, Outubro de 2010).

Estranhamente, os livros didáticos de geografia, inclusive os que vem com a marca da "geografia crítica" chancelada pelo MEC nas suas capas, apenas reforçam este conteúdo mergulhado em medo, porque trabalham com a escala da nação, do território, aonde sujeitos genéricos não tem rosto ou nome, constituindo sempre massa coletiva, criando um "vácuo" na aprendizagem dos vicinais, que se revela no tédio de muitos estudantes diante de um conteúdo que pouco lhes diz respeito e um apelo ao território nacional como comunidade para além de sua conflitualidade, sentida na pele pelos estudantes e suas famílias.

Estamos diante de uma situação-limite (JASPERS, 1958), produtora de um sofrimento inevitável e contra ao qual não se pode escapar ou construir um sentido - porque não se compreende ou não se quer compreender a situação - tomando conta da existência, não pontual, mas constantemente.

A construção de uma comunicação existencial entrelugares, poderia ser uma maneira de afirmar a existência conflituosa dos mesmos e explicitá-las nos conteúdos geográficos, ou seja, uma geografia em ato que inexiste e decreta inexistências nos lugares (o que existe é o território nacional e, quando muito, a região Amazônica), dada a sua generalidade e sua ausência de ação comunicativa (HABERMAS, 2012), o que empobrece o reconhecimento de si, do outro e de sua própria situação nos lugares, uma situação-limite (JASPERS, 1958), que poderia ser compreendida para ser enfrentada, mas passa a ser uma normalidade instituída: o silêncio.

Interessante, porém, como a linguagem dos Filhos de Adão, de maneira subversiva neste espaço de fricção entrelugares recoloca a geograficidade em criação, seja nas rodas de canto que tematizam a farinha, seja no enfrentamento da dor da separação dos filhos que terão que estudar na cidade; seja na poética do trabalho na terra que aparece em forma de cordel e num encantamento com a floresta ou nas falas de desespero pelo isolamento e falta de condições de vida (Cf. Quadro 1).

É uma linguagem que se realiza em um misto de fala nordestina e paraense, com a marca da terra e da crença partilhada. Linguagem ignorada pelo conteúdo disciplinar que, ao d interrompe um agir comunicativo, desviando dos anseios e energias dos lugares e entrelugares vicinais como exercício do saber geográfico o que nos faz mais ignorantes sobre nós mesmos e a realidade diferencial brasileira. 


\section{VOLTANDO DA BEIRA - IMPRESSÕES IMERSIVAS}

Este texto pretendeu dialogar, ao menos em princípio, como o lugar das vicinais transamazônicas e, sobretudo, explicitar como a geografia concorre para auxiliar a "leitura de mundo" dos estudantes nestes lugares.

Claro está que não basta localizar geograficamente os lugares, é preciso compreender sua lugaridade singular em relação aos outros lugares, é preciso engajamentos corpóreos para que os mesmos deixem de ser simples pontos, para constituírem densos de sentido comunicativo, mesmo que não translúcidos para nossa avidez de explicação dos outros. Esta possibilidade implica um tipo de comunicação ativa, recíproca e não contemplada nos livros didáticos, genéricos na abordagem e distanciados das vivências, porque centrados na escala do território, passam não apenas a invisibilizar, mas concorrem para afirmar inexistência dos lugares na medida em que os estudantes e professores não se reconhecem no saber que lhes é provocado e são sufocados pela fratura de linguagem de mundo (e não falo aqui no sentido de norma culta/coloquial, mas da moldura da fala significativamente diferente entre o conteúdo padrão e o vivido).

Além disso, a incomunicabilidade existencial produz o silêncio entrelugares, o que reforça um tipo de estratégia de controle normalizado, que apaga os conflitos e mantém o tipo de conhecimento geográfico oficial (pedagogizado, didático) que pouco auxilia na compreensão da existência dos que vivem à beira da Transamazônica, tanto para os de fora (como conhecimento), mas, sobretudo, para os de dentro (como vivência).

\section{REFERÊNCIAS}

1. ANDERSON, B. Comunidades imaginadas. Reflexões sobre a origem e difusão do nacionalismo. São Paulo: Cia das Letras, 2008.

2. ARAÚJO, R. et. all. Estado e Sociedade na BR-163: desmatamento, conflitos e processos de ordenamento territorial. In: CASTRO, E. (Org.) Sociedade, Território e Conflitos: BR-163 em questão. Belém: NAEA, 2008.

3. AUGÉ, M. Não-lugares: introdução a uma antropologia da supermodernidade. Campinas: Papirus, 1994.

4. BECKER, B. Redefinindo a Amazônia: o vetor técnico-ecológico. In: CASTRO, I. E.; GOMES, P. C. C.; CORREAA, R. L. (Orgs.) Brasil: questões atuais e reorganização do território. $2^{\mathrm{a}}$ ed. Rio de Janeiro: Bertrand Brasil, 2002.

5. BERDOULAY, V;; ENTRIKIN, N. Lugar e Sujeito? Perspectivas teóricas. In: MARANDOLA Jr., E.; HOLZER, W.; OLIVEIRA, L. Qual o Espaço do Lugar? São Paulo: Perspectiva, 2012. 
6. BHABHA, H. K. O Local da Cultura. $2^{\text {a }}$ ed. Belo Horizonte: Editora ufmg, 2013

7. BONFIM, N. R. Representações sociais do espaço e ensino de geografia. IN: BONFIM, N. R.; ROCHA. L. B. (Orgs.) As Representações na Geografia. Santa Cruz/BA: Editus/UESC, 2012.

8. COELHO, M. C. N. A CVRD e a (re)estruturação do espaço geográfico na área de Carajás (Pará). CASTRO, I. E.; GOMES, P. C. C.; CORRÊA, R. L. (Orgs.) Brasil: questões atuais e reorganização do território. $2^{\text {a }}$ ed. Rio de Janeiro: Bertrand Brasil, 2002.

9. COMISSÃO PASTORAL DA TERRA. http://www.cptnacional.org.br/, acesso em 03.01.2016.

10. CERBONE, D. R. Fenomenologia. São Paulo: Vozes, 2012.

11. DARDEL, E. O Homem e a Terra. Natureza da Realidade Geográfica. São Paulo: Perspectiva, 2011.

12. FEYERABEND, P. Adeus à Razão. São Paulo: Editora Unesp, 2010.

13. GONÇALVES, C. V. P. Amazônia, Amazônias. São Paulo: Contexto, 2012.

14. JASPERS, K. Filosofia. Tomos I e II. Madrid: Universidade de Puerto Rico, 1958.

15. . Introdução ao Pensamento Filosófico. São Paulo: Cultrix, 2011.

16. HABERMAS, J. Teoria do Agir Comunicativo. Racionalidade da Ação e a Racionalização Social \& Sobre a Crítica da Razão Funcionalista. vol. 1-2. São Paulo: WMF Martin Fontes, 2012.

17. HAESBAERT, R.; LIMONAD, E. O território em tempos de globalização. Revista Etc... espaço, tempo e ciência. n. 2 (4), v. 1, 2007. Disponível em: http://www.uff.br/etc/UPLOADs/etc\%20 2007_2_4.pdf, acesso em 07.06.2014.

18. HAESBAERT, R. Viver no Limite. Rio de Janeiro: Bertrand Brasil, 2014.

19. HAGE, S. M. Desafios da educação rural no Estado do Pará/Região Amazônica. In: HAGE, S. M. (Org.). Educação do Campo na Amazônia. Retratos de Realidade das Escolas Multisseriadas no Pará. Belém: Gráfica e Editora Gutemberg, 2005.

20. ___ Por uma escola do campo de qualidade social: transgredindo o paradigma (multi) seriado de ensino. Em Aberto, Brasília, v. 24, n. 85. Pp. 97-113, 2011. Disponível em: http:// rbep.inep.gov.br/index.php/emaberto/article/viewFile/3956/2284, acesso em 03.01.2016.

21. HANCIAU, N. J. O Entrelugar. In: FIGUEIREDO, E. Conceitos de literatura e cultura. Juiz de Fora:Editora UFJF/Niterói:EdUFF, 2005. Disponível em: http://hanciau.net/arquivos/Entre_ lugar.pdf. Acesso em 09.10.2016.

22. HEIDEGGER, M. Ser e Tempo. São Paulo: Unicamp/Vozes, 2012.

23. HONDA, Y. F.; SEPÊDA FILHO, M. G.; PANTOJA, W. W. R. As diversas formas de planejar o espaço amazônico: uma visão sobre o caso de Pacajá - PA. CODS - Colóquio Organizações, Desenvolvimento e Sustentabilidade. pp. 195-206. Disponível em: www.unama.br/seer/index. $\mathrm{php/coloquio/article/download/108/pdf,} \mathrm{acesso} \mathrm{em:} \mathrm{12.11.2014.}$

24. LUIJPEN, A. M. Introdução a Fenomenologia Existencial. São Paulo: Editora Universitária da USP, 1973. 
25. MALPAS, J. Thinking Topographically: Place, Space, and Geography, 2013. Disponível em: http://jeffmalpas.com/wp-content/uploads/2013/02/Thinking-Topographically-Place-Spaceand-Geography.pdf, acesso em 02.05.2015.

26. MASSEY, D. Pelo Espaço. Por uma política da espacialidade. Rio de Janeiro: Bertrand Brasil: 2009.

27. MERLEAU-PONTY, M. O Visível e o Invisível. São Paulo: Perspectiva, 2012.

28. MOREIRA, E. Ideias para uma Concepção Geográfica da Vida. Organizado por Maria Stella F. P. Guimarães. Belém: SEMEC, 2012.

29. NAHUM, J. S. Região e Representação: A Amazônia nos PDAs. Geocrítica, v. XVII, n. 985, 2012. Disponível em: http://www.ub.edu/geocrit/b3w-985.htm, acesso em 12.05.2014.

30. OLIVEIRA, A. N.; LIMA, M. I. R. Assentamento do Cururuí, Núcleo D: O Espaço como Lugar de Vivências no Limite da Humanidade (2007-2013). Trabalho Acadêmico de Conclusão (Licenciatura em Geografia), IFPA, 2014 (mimeo).

31. OLIVEIRA NETO, A. A luta pela educação do campo: uma conquista em processo. Revista Geoamazônia, v. 2, n. 4, pp. 159-172, 2015. Disponível em: http://geoamazonia.net/index. $\mathrm{php/revista/article/view/50,} \mathrm{acesso} \mathrm{em} \mathrm{05.01.2016.}$

32. RELPH, E. Reflexões sobre a Emergência, Aspectos e Essência do Lugar. In: MARANDOLA Jr., E.; HOLZER, W.; OLIVEIRA, L. Qual o Espaço do Lugar? São Paulo: Perspectiva, 2012.

33. SAITO, E. A.; et. all. Análise de padrões de desmatamento e trajetória de padrões de ocupação humana na Amazônia usando técnicas de mineração de dados. In: Anais do XV SBSR, Curitiba, 2011. Disponível em: http://www.ltid.inpe.br/sbsr2011/files/p0747.pdf, acesso em 12.06.2013.

34. SANTOS, M.; SILVEIRA, M. L. O Brasil: sociedade e território no início do século XXI. 16a Ed. São Paulo/Rio de Janeiro: Record, 2012.

35. SILVEIRA, M. L. Uma situação geográfica: do método à metodologia. Revista TERRITÓRIO, ano IV, no 6, jan./jun. 1999. Disponível em: http://www.revistaterritorio.com.br/pdf/06_3_ silveira.pdf, acesso em 08.10.2016.

36. SCHMID, C. A teoria da produção do espaço de Henri Lefebvre: em direção a uma dialética tridimensional. In: Geousp, n. 32, pp. 89-109, 2012. Disponível em: http://www.revistas.usp. br/geousp/article/view/74284/77927, acesso em 12.08.2015.

37. SARTRE, J.P. Crítica da Razão Dialética. Precedido de questão de método. São Paulo: DP\&A, 2002.

38. TAMER, A. Transamazônica. Solução para 2001. 2a ed. São Paulo/Rio de Janeiro: APEC, 1971.

39. TUAN, Y. F. Espaço e Lugar. A perspectiva da experiência. Londrina: EDUEL, 2013.

40. YAZBEK, A.C. Cadernos de Ética e Filosofia Política v. 13, n. 2, 2008, p. 153-163. Disponível em: http://www.revistas.usp.br/cefp/article/view/83389/86397, acesso em 28.01.2016.

ARTIGO RECEBIDO EM ABRIL DE 2017

ARTIGO ACEITO EM JUNHO 2017 